\title{
Hidroituango revisitado. Contextualización y reflexiones desde un conversatorio
}

Hydroituango revisited. Contextualization and reflections from a conversation

Mercedes Castillo de Herrera

Universidad Santo Tomás . Economista, con estudios en filosofía, MSc. y doctora en urbanismo. Docente Universidad Santo Tomás.

Correo electrónico: mercedescastillo@ustadistancia.edu.co 


\section{Resumen}

Hidroituango es el megaproyecto eléctrico más grande en la historia de Colombia, una de las empresas más ambiciosas que el país ha emprendido en las últimas décadas. Con su implementación se pretende generar 2.400 MW de energía, $17 \%$ de la producción total del país. Su construcción se inició en 2009 y su funcionamiento, esperado para 2018, no ha comenzado por supuestas fallas geológicas y afectaciones por lluvias. A comienzos de 2019, se produjeron deslizamientos de tierras, taponamientos de los túneles y el cierre del flujo del río por parte de EPM, lo que desató fuertes debates en el país por las afectaciones a las poblaciones. La Universidad Santo Tomás, buscando construir reflexiones que contribuyeran con la generación de estrategias para afrontar una situación tan crítica, abrió un escenario para el análisis de Hidroituango. El evento comenzó con una contextualización histórica y técnica, pero no se hizo una contextualización de la problemática social, económica y política que han vivido las comunidades indígenas cañoneras desalojadas de sus territorios, de la pérdida de redes sociales y de una forma de vida con saberes ancestrales asociados al barequeo, la pesca y la arriería. El objetivo del presente artículo es retrotraer de manera resumida las respuestas de los invitados, iniciando con la necesaria contextualización realizada a partir de revisión bibliográfica, que en su momento no fue posible por cuestiones de tiempo y que es imprescindible por respeto a comunidades cuyo oficio estaba próximo a ser reconocido Patrimonio Cultural Inmaterial y, en lugar de ello, fueron despojados de sus tierras, sus formas de vida y de subsistencia. Sobra decir que este artículo recoge únicamente el pensar de la autora.

Palabras clave: Hidroituango, conversatorio, comunidades indígenas cañoneras del Cauca, despojo, extractivismo, megaproyectos, Universidad Santo Tomás.

\section{Abstract}

Hidroituango is the largest electric megaproject in the history of Colombia, one of the most ambitious draft that the country has undertaken in recent decades. Its implementation aims to generate 2,400 MW of energy, 17\% of the country's total production. Its construction began in 2009 and its operation, expected for 2018, has not started due to alleged geological failures and rainfall effects. At the beginning of 2019, there were landslides, blockages of the tunnels and the closure of the river flow by EPM, which sparked strong debates in the country due to the effects on the populations. Universidad Santo Tomás, seeking to build reflections that contribute to the generation of strategies to face such a critical situation, opened a scenario for Hidroituango's analysis. The event began with a historical and technical contextualization, but there was no contextualization of the social, economic and political problems experienced by the indigenous communities that have been deslocated from their territories, the loss of social networks and a way of life with knowledge ancestral associated to barequeo, the fishing and the muleteer. The objective of this article is to roll back, in a summary way, the speakers' responses, starting with the necessary contextualization made from bibliographic revision, which was not possible 
at the moment, due to time issues, but it is essential for respect to communities whose job was next to be recognized Intangible Cultural Heritage and, instead, they were dispossessed from their lands, their ways of life and subsistence. Needless to say that this article includes only the author's thinking.

Keywords: Hidroituango, conversation, indigenous communities of the Cauca canyon, dispossession, extractivism, megaprojects, Universidad Santo Tomás.

\section{Introducción}

El día 19 de febrero de 2019 se celebró en la Universidad Santo Tomás el Primer conversatorio sobre la situación de la Central Hidroeléctrica Pescadero Ituango S.A. E.S.P, Hidroituango, un diálogo para construir soluciones, con el fin de "realizar una profunda reflexión sobre los fundamentos éticos, sociales y ambientales que conlleva el desarrollo de megaproyectos en el país [así como] solidarizarnos y a responder de forma responsable con la situación actual de las comunidades aledañas del río Cauca que viven en medio de la incertidumbre a causa del deterioro y la pérdida de sus medios de vida" (Invitación al conversatorio).

La convocatoria, realizada por el programa de Administración Ambiental y de los Recursos Naturales, la especialización en Ordenamiento y Gestión Integral de Cuencas Hidrográficas y la maestría en Gestión Integral de Cuencas Hidrográficas de la División de Educación Abierta y a Distancia, así como la Dirección de Responsabilidad Social Universitaria, la Coordinación de Gestión Ambiental, la
UGICU, la maestría en Planeación para el Desarrollo, la Facultad de Ingeniería Ambiental y la Facultad de Sociología, aglutinó 965 personas en los auditorios de Bogotá y Medellín y fue seguido de manera virtual por cerca de 4.100 personas más a través de Facebook lite y Blackboard Collaborare.

En el momento del conversatorio, el país enfrentaba un álgido debate puesto que el megaproyecto eléctrico más grande en la historia de Colombia y una de las empresas más ambiciosas que el país ha emprendido en las últimas décadas, el proyecto "Hidroeléctrica Pescadero Ituango S.A. E.S.P", que pretendía generar 2.400 MW de energía, equivalentes al $17 \%$ de la producción total del país, había iniciado obras en 2009 esperando entrar en funcionamiento en 2018, pero en 2019 se empezaba a conocer que no había habido estudios de suelo suficientes y ya se habían presentado casos de remoción en masa, taponamiento de túneles y fugas que obligaron a cerrar el flujo del río, afectando a miles de personas aguas abajo.

Fue así como el moderador del conversatorio, el padre Javier Antonio Castellanos, O.P., decano de División de Educación Abierta y a Distancia, planteó a los invitados las siguientes preguntas:

- ¿Cuáles son las compensaciones y acciones puntuales que ustedes recomiendan debe tomar EPM y las demás empresas involucradas para mitigar y restaurar los ecosistemas dañados?

- ¿Qué acciones puntuales pueden llevarse a cabo para disminuir la afectación social y económica de las cerca de 
35.000 personas afectadas directamente por el proyecto, que han perdido su principal medio de subsistencia?

- Tenemos un dato, que en concordancia con el informe entregado por la Contraloría General de la República en el que de los 35 hallazgos, 29 tuvieron presunta incidencia disciplinaria y 8 penales, ¿Usted cree que la crisis de Hidroituango se debe más a las fallas de control en el cumplimiento de las normas técnicas, o la falta de capacidad de EPM y las demás empresas involucradas en desarrollar este tipo de megaproyecto?

- ¿Cómo la crisis de Hidroituango afecta al colombiano de a pie, al que ve todo por la TV pero no vive en los municipios afectados?

Los invitados en esta ocasión fueron la socióloga e historiadora Isabel Cristina Zuleta, vocera de las comunidades afectadas por el megaproyecto Hidroituango articuladas en el Movimiento Ríos Vivos Antioquia'; Orlando Rangel, doctor en biología de la Universidad de Ámsterdam, en Holanda y profesor titular del Instituto de Ciencias Naturales de la Universidad Nacional de Colombia; Luz Fernanda Jiménez Segura, doctora en biología de la Universidad de Antioquia y profesora del Instituto de Biología de la misma universidad; Víctor Julio Atencio García, ingeniero pesquero, docente y director del Instituto de Investigaciones Piscícolas de la Universidad de Córdoba; Jorge Alberto Sánchez Espinosa, antropólogo,

1. Tras diez años liderando acciones de resistencia hacia Hidroituango y exigiendo la libertad de los ríos en Colombia, Zuleta fue galardonada con el premio nacional a la defensa de los derechos humanos como proceso colectivo del año 2019. doctor en Suelos de la Universidad Nacional de Colombia y docente de la Universidad Santo Tomás y Hernán Sánchez Cruz, biólogo de la Universidad Nacional de Colombia y director de la Unidad Gestión Ambiental y Social Generación energía de EPM.

El objeto del presente artículo es recoger de manera resumida varias de las respuestas que se dieron en este conversatorio por parte de los invitados, pero primero desarrollar la necesaria contextualización, imprescindible por respeto a las comunidades cuyo oficio estaba próximo a ser reconocido Patrimonio Cultural Inmaterial y, en lugar de ello, fueron despojados de sus tierras, sus formas de vida y de subsistencia

\section{Materiales o recursos}

Para cumplir con el objetivo de este artículo se tomaron las transcripciones del evento que realizamos la profesora Betsy Bello y yo y que fueron publicadas en la página de la universidad Santo Tomás y se editaron, para evitar repeticiones, pero cuidando de ser muy fiel en el sentido de las respuestas y de no perder el estilo del entrevistado. Para la primera parte del desarrollo se realizó una revisión bibliográfica que permitiera contextualizar social y económicamente la problemática planteada. Se seleccionaron artículos más o menos recientes que trataran ese tema específico. Igualmente, una pequeña revisión de prensa permitió comprender los eventos que desataron la crisis y que se trataron en el conversatorio. 


\section{Resultados y/o discusión}

\section{El comienzo del proyecto}

Como muchos de los megaproyectos desarrollados en el país, si no todos, ${ }^{2}$ el proyecto Hidroituango se publicitó como la oportunidad de generar empleo, desarrollo y bienestar para los colombianos al convertir un territorio abandonado y excluido, como lo era el cañón del río Cauca en "la fuente de ingresos permanente que permitirá al Departamento oxigenar sus rentas -durante los próximos cien años- y por ende realizar con generosidad esa inversión social sin precedentes, de la que invariablemente se deriva la paz soñada".

La historia de la hidroeléctrica empezó hace cincuenta años, cuando el ingeniero José Tejada Sáenz empezó a impulsar el sueño de generar energía con las aguas del río Cauca, que comenzó a concretarse 25 años después, en 1995, cuando el entonces gobernador de Antioquia Álvaro Uribe creó la Sociedad Promotora de Pescadero Ituango y formalizó el proyecto de la Hidroeléctrica (Fernández \& Caballero, 2011, en Gómez, 2015). A pesar de considerar inviable el proyecto durante muchos años, Empresas Públicas de Medellín, EPM, decidió en 2008 comenzar el proyecto que mejoraría la vida de los doce municipios del norte y occidente de Antioquia ${ }^{3}$ : de Ituango y Briceño, en donde se localizan las obras principales, y

2. Palabras de Luis Alfredo Ramos, gobernador de Antioquia para la época, en Cardona, Pinilla y Galviz (2016, p. 305).

3. La presa está localizada a unos $8 \mathrm{~km}$ aguas abajo del puente de Pescadero, sobre el río Cauca, en la vía a Ituango, inmediatamente aguas arriba de la desembocadura del río Ituango al río Cauca (http:// www.grupo-epm.com, 2017). de Santa Fe de Antioquia, Buriticá, Barbacoas (Peque), Liborina, Orobajo (Sabanalarga), Toledo, Olaya, San Andrés de Cuerquia, Valdivia y Yarumal, que aportan predios para las diferentes obras del proyecto. (EPM, 2017). La licencia ambiental se obtuvo en 2009, lo que permitió comenzar la construcción de las vías de acceso y en 2010 se terminaron los diseños para la obra.

\section{Conflictos políticos y grupos armados}

Como afirman varios autores, hay una gran coincidencia entre eventos del conflicto armado en la región y la creación del megaproyecto hidroeléctrico (Fernández \& Caballero, 2011; Gómez, 2015; Cardona, Pinilla \& Gálvez, 2016; Rutas del Conflicto, 2019; Vidas silenciadas, 2013; Agencia Prensa Rural, 2019). Si bien es cierto que en este territorio existió una disputa histórica entre el Estado y los grupos armados subversivos por su control, a partir de los años noventa del siglo pasado comenzó el control paramilitar por medio de las Autodefensas Unidas de Colombia, AUC, que perpetraron 62 masacres en los doce municipios donde se desarrolla la obra, varias de ellas en investigación, hechos reconocidos por los hermanos Castaño y por Salvatore Mancuso en sus declaraciones al ser capturados. Estas se registraron en:

Ituango donde se presentaron 11 masacres que dejaron un total de 71 víctimas, Valdivia (11 masacres y 68 víctimas), Yarumal (6 masacres y 38 víctimas), San Andrés de Cuerquia (5 masacres y 32 vítimas), Santa Fe de Antioquia (5 masacres y 23 víctimas), Buriticá (5 masacres y 22 víctimas), Peque (4 masacres y 31 
víctimas), Briceño (4 masacres y 19 víctimas), Sanbanalarga (4 masacres y 26 víctimas), Toledo (4 masacres y 23 víctimas), Liborina (3 masacres y 19 víctimas), para un total de 372 asesinatos en esa zona.

Además, de acuerdo con el Centro Nacional de Memoria Histórica, en la zona de influencia de Hidroituango se cree que hay 643 víctimas de desaparición forzada. El Registro Único de Víctimas contabiliza 622, mientras que el Registro Nacional de Desaparecidos señala que son 343. (Agencia Prensa Rural, 2019)

Varias ONG creen que en el cañón del río Cauca hay entre 300 y 600 víctimas enterradas que quedarán irremediablemente en el olvido tras el llenado de la represa (Movimiento Ríos Vivos). De la misma forma, durante la construcción del proyecto se ha producido la militarización de los territorios, la conformación de batallones para vigilar la zona donde se construyen las obras, desprotección de los sectores campesinos, criminalización de la protesta, amenazas y hasta asesinatos de personas que intervienen en las protestas (Gómez, 2015).

Con la entrada en vigencia de la Jurisdicción Especial para la Paz, JEP, se reveló que en los 12 municipios del área de influencia se presentaron entre 1985 y 2012 más de 950 casos [de desapariciones], sin embargo, en la audiencia solo se toman los municipios de Briceño, Ituango, Peque, Sabanalarga, Toledo y Valdivia donde entre 1995 y 1999 hubo 187 desapariciones, que se duplicaron en el quinquenio 2000-2004 a 300. De las 667 desapariciones que se registran en los seis municipios, se ha determinado que 278 son de paramilitares, 116 de las Farc, 96 de grupos armados desconocidos y 10 de agentes del Estado. (Revista Semana, 10 de agosto de 2019)

Por esta razón, la JEP convocó a una audiencia pública para determinar si EPM e Hidroituango S.A. hicieron lo necesario para buscar a dichos desaparecidos o, por el contrario, actuaron sin tomar las medidas necesarias. Igualmente, la JEP también busca que se aclare la situación del pueblo indígena $\mathrm{Nu}-$ tabe, víctima de esta violencia por la masacre de 1998 donde fue asesinado su último cacique, Virgilio Sucerquia, junto con otros cinco indígenas y a los cuales se les desconoció su pertenencia étnica para no desarrollar la consulta previa que todo proyecto de infraestructura o explotación de recursos debe realizar en territorios ancestrales de pueblos indígenas y grupos étnicos.

\section{Conflictos sociales (sociopolíticos) y despojo}

La población que habitaba estas laderas eran comunidades mestizas precarias portadoras de saberes indígenas, pequeños productores de café y productos de pancoger que combinaban sus actividades con el barequeo ${ }^{4}$

4. Desde el año 2012, los barequeros Francisco Luis Salazar, de Mogotes (Buriticá), Gregorio Chavarría, de San Andrés de Cuerquia, y Guillermo Builes, de Sabanalarga, con la profesora Neyla Castillo-adscrita al Grupo de Investigación Recursos Estratégicos, Región y Dinámicas Socioambientales (RERDSA) y al Instituto de Estudios Regionales (INER) de la Universidad de Antioquia- presentaron una solicitud para la inclusión del barequeo en la Lista Representativa de Patrimonio Cultural Inmaterial (LRPCI) del ámbito departamental gestionada por la Gobernación de Antioquia, y del ámbito nacional, gestionada por el Ministerio de 
y la pesca, o arrieros que intercambiaban los bienes obtenidos en los diversos pisos térmicos del cañón y con muy fuertes redes sociales tejidas entre ellos (Cardona, Pinilla \& Gálvez, 2016). La actualización del estudio de Impacto Ambiental de EPM Ituango (2011), lo describe en los siguientes términos:

Como parte de la adaptación de las comunidades al entorno se han desarrollado fuertes relaciones de vecindad y reciprocidad entre los mineros que intercambian mercancías con los campesinos de las partes medias y altas de la montaña, y los arrieros, que reparten mercancías por todo el territorio. (EPM Ituango, 2011, citado por Torres, Caballero \& Awad, 2016)

Desde un comienzo, las comunidades manifestaron su preocupación y hubo voces desde diferentes sectores que advirtieron que el represamiento del río Cauca para construir el embalse de Hidroituango iba a despojar a las poblaciones de sus tierras, de sus medios de subsistencia, a borrar la continuidad del barequeo como eje de las poblaciones asentadas en la terrazas aluviales sobre el río y las laderas de las cordilleras central y occidental que configuran el cañón y que se iba a producir "un proceso de vaciamiento y reescritura de sentido que postula al cañón como un territorio sacrificable en pos de la construcción de un emprendimiento extractivista que desconoce la ocupación secular de comunidades locales practicantes de la minería de oro corrido o barequeo" (Cardona, Pinilla \& Gálvez, 2016, p. 304).

Cultura (Salazar et al., 2013, p. 9, citado por Cardona, Pinilla \& Gálvez, 2016, p. 309).
El desarrollo del proyecto produjo, no sólo el despojo de las tierras y el desplazamiento de sus habitantes, sino que conllevó la destrucción de sus cultivos y viviendas, la interrupción del acceso al río y a sus playas, la ruptura de redes sociales y pequeñas economías locales, la pérdida de elementos históricos y culturales y de los medios de subsistencia de todas estas familias (Gómez, 2015). Las comunidades se convirtieron en invasoras de sus propios territorios.

Lo anterior se traduce en un fuerte sentimiento de desarraigo material, social y cultural por la pérdida de los espacios de uso y ocupación cotidianos, y la ruptura de las relaciones de parentesco y vecindad, de singular importancia en la generación de mecanismos de cohesión y solidaridad entre los habitantes de la parte baja del cañón, conocidos como "cañoneros", y las personas que habitan las partes medias y altas, conocidos como "montañeros". (Torres, Caballero \& Awad, 2016)

Lo que es peor, es que las comunidades, las autoridades locales e incluso los mismos funcionarios de las empresas contratistas, desconocían las implicaciones del proyecto y sus planes de manejo; desde 2008 las comunidades están pidiendo que se les explique el proyecto y han sido ignoradas (Torres, Caballero \& Awad, 2016).

\section{Conflictos ambientales (o socioambientales)}

Los conflictos ambientales, a pesar de contar con una licencia ambiental, comienzan con los 
movimientos de tierra, las excavaciones de pozos, la construcción de campamentos, la desviación del río Cauca para facilitar la construcción del muro, la destrucción de la vegetación, los daños a la fauna silvestre, el bloqueo de la migración de peces y la contaminación del aire y del agua como resultado de la construcción y la eliminación de los residuos (Gómez, 2015).

Esto sucede porque la fuente hídrica queda bajo el control de la empresa de energía, mientras que las poblaciones que se venían beneficiando de ella para sus actividades productivas, pesca y agricultura y barequeo, pierden el acceso. La construcción del proyecto implicó la inundación de cerca de 70 kilómetros del cañón del Cauca para el llenado de la presa y la afectación de la pesca (Cardona, Pinilla \& Gálvez, 2016).

\section{Cronografía de las dificultades técnicas del proyecto}

Jorge Sánchez, docente del programa de Administración Ambiental y de los Recursos Naturales de la Universidad Santo Tomás, desarrolló la cronografía de dificultades que desataron la crisis de Hidrotuango y que sirvieron como contextualización del evento. En esta se mencionaba que el 28 de abril de 2018, el proyecto Hidroituango sufrió un deslizamiento que causó el taponamiento de uno de los túneles de desviación del río Cauca, lo que terminó desencadenando una serie de emergencias que obligaron a la empresa, y a los organismos de control del riesgo, a evacuar a más de 5.000 personas río abajo por el riesgo de que se presentara una avalancha de grandes proporciones. El 1 de mayo se presentó el segundo taponamiento en otro de los túneles de la obra y el 3 de mayo el puente de Pescadero, construido como vía de comunicación entre Medellín e Ituango, desapareció bajo el agua represada.

El 9 de mayo, EPM aceptó que el daño en el túnel ponía en riesgo el cronograma de actividades que había fijado la entrada en operaciones para el 30 de noviembre. Ese mismo día, la empresa tuvo un respiro e informó que uno de los tres túneles originales de evacuación de agua del proyecto hidroeléctrico Ituango se había destapado, por lo cual el río Cauca comenzaba a fluir. Sin embargo, el 10 de mayo se decide inundar la casa de máquinas antes de terminar la obra, con lo que se corría el riesgo de que el macizo rocoso cediera (Rivera, 2019), lo que constituye el revés más duro sufrido por Hidroituango en los 22 días de crisis.

El 12 de mayo, cuando se creía que el problema se estaba resolviendo, un destaponamiento natural produjo una crecida estrepitosa en el caudal del río Cauca y este causó daños en el casco urbano del corregimiento de Puerto Valdivia y generó alerta y orden de evacuación en otros municipios de su zona de influencia. Al menos 600 personas se vieron afectadas, 25 casas fueron destruidas, 34 quedaron inhabitables, tres puentes peatonales desaparecieron, hubo averías en la escuela local y destrucción en el centro de salud. El 14 de mayo, el gobernador de Antioquia, Luis Pérez se vio en la necesidad de declarar la calamidad pública tras lo ocurrido y al día siguiente manifestó que EPM le había ocultado información sobre lo que sucedía. El 16 de mayo una nueva emergencia sacudió el proyecto obligando a la Unidad Nacional de Gestión del Riesgo de Desastres, UNGRD y EPM a lanzar una alerta 
para que se evacuara Puerto Valdivia, Valdivia, Cáceres, Tarazá, Nechí, Caucasia, zonas bajas de San Benito Abad, Caimito y Guarandá en Sucre.

El miércoles 9 de enero de 2019, cuando había una relativa calma, los constructores hallaron un ahuecamiento cercano a la casa de máquinas por donde se sentían ráfagas de viento, que volvió a prender las alarmas en torno al megaproyecto hidroeléctrico. Esta cárcava o ahuecamiento, de entre 18 y 40 metros, obligó a acelerar el cierre de las compuertas de la casa de máquinas, operación que se haría entre el miércoles 16 y viernes 18 de enero, según se informó en el Puesto de Mando Unificado, PMU, conformado por autoridades del orden nacional, departamental y municipal, así como por EPM.

El jueves 7 de febrero de 2019, la revista Semana publicaba:

el río Cauca, portentoso, que desde lejos parecía tener la fuerza suficiente para revolcar el mundo, ya no está. Desapareció el color de siempre: pantanoso, café, oscuro. Ahora es un agua clara, verdosa y mansa, una quebrada. Algunos peces luchan por sobrevivir en las piedras y los pescadores, manicruzados, ven ese río extraño que ahora les envían desde Hidroituango como si fuera un animal muerto.

Es raro -dicen los hombres entre las piedras y los remolinos de tierra desde donde exuda un aroma a pescado que calcina el aire- pero sabían que esto iba a suceder. Dicen que sabían que la idea de controlar el río Cauca se le iba a salir de las manos a EPM y que se convertiría en una tragedia. Y que si existe una tragedia muy grande es la de perder un río. Un río que es una cosa viva, enorme, poderosa, dicen. Lo conocen, y así mismo le temen. Una casa se cae, un puente se viene abajo, un carro se hace pedazos, ¿pero cómo detienen un río, como lo desaparecen de su lecho?". (Rivera, 2019)

Aun así, la alerta se mantuvo en el norte de Antioquia, precisamente porque todavía había situaciones por resolver en el proyecto hidroeléctrico más importante del país. Mientras continúa la incertidumbre de lo que va a pasar con Hidroituango, por un lado EPM insiste en mostrar que es viable; y por otro, algunos sectores gremiales de la ingeniería, de la geología, políticos y sociales y la organización Ríos Vivos Antioquia y otros proponen desmontar la hidroeléctrica para que no haya más riesgos ambientales y geológicos alrededor del proyecto. Las metas actuales del proyecto son continuar con el llenado prioritario de la presa, subiendo hasta la cota 415 , como un seguro adicional, así como tapar el túnel de desviación derecho, que ha presentado obstrucciones y destaponamientos desde el pasado 28 de abril de 2018. Adicionalmente la empresa está trabajando para tapar el sistema auxiliar de desvío.

\section{Primera pregunta: \\ ¿Cuáles son las compensaciones y acciones \\ puntuales que ustedes recomiendan debe tomar \\ EPM y las demás empresas involucradas para mitigar y restaurar los ecosistemas dañados?}

Orlando Rangel: en primer lugar debo decir que yo soy parte de la culpa porque soy parte 
de una comunidad académica que no fijó su voz de alarma a tiempo. Ya el daño está hecho ahora el asunto son las compensaciones. Aquí tenemos que trabajar con el método de comparación, tenemos un caso muy importante como es el de Urrá y lo que le ha pasado a la gente del Sinú. Casi siempre estas obras que van a favorecer a muy pocos y a desfavorecer a la mayoría tienen un periodo, como una garantía, de siete $u$ ocho años para restauración de las condiciones iniciales. En Urra esos siete u ocho años no sirvieron para nada y después de que se terminó el proyecto fue el gobierno el que tuvo que entrar a remediar. ¿Cuál es el problema mayor? Las afectaciones, especialmente, en las pesquerías de los ribereños. Hay que mirar cómo se le dignifica un poco el asunto a toda esta gente, porque vienen las repoblaciones de peces, pero son demasiado escasas porque siete $u$ ocho años es un tiempo muy corto. Las represas mismas tienen una vida media de cincuenta años, nuestras obras de ingeniería lo han estimado así, pero ese tiempo es insuficiente para la restitución, la restauración del medio natural, es absolutamente ridículo creer que en cincuenta años se va a lograr siquiera recuperar el cuarenta por ciento de lo que tenemos. Los estudios en diferentes regiones naturales de Colombia muestran que en un período de cuarenta años ni siquiera se ha recuperado el treinta por ciento de la riqueza y la biodiversidad que existía antes del proyecto, entonces, lo que queda es pedir que al menos en las compensaciones, en las previsiones, se extienda ese plazo siquiera a unos cuarenta o cincuenta años para que las compañías respondan con todo lo que significa restaurar y mitigar los impactos.

Isabel Cristina Zuleta: cualquier acción de compensación requiere que ésta sea, necesa- riamente, construida participativamente con las comunidades afectadas. La primera acción es que seamos escuchados y escuchadas porque lo que ha hecho el proyecto hidroeléctrico Hidroituango es ocultar nuestra voz, minimizar la voz de las comunidades organizadas y de las no organizadas. Entonces, la primera acción es que se nos pregunte y construir colectivamente, porque allá no se está construyendo colectivamente, porque no hay un proceso participativo, no hay un proceso comunitario, no hay una voz real y cuando otras personas hablan en nombre de las comunidades, realmente no han consultado si quiera con esas comunidades, entonces cualquier acción por más benéfica que parezca no lo va a ser si están decidiendo sobre mi vida. Así es que el primer llamado es que los que estamos allá, los que habitamos el territorio de la represa, tengamos la posibilidad de decidir sobre nuestra vida, sobre nuestro riesgo, integridad física porque es lo que acaba de pasar con tantas emergencias, nos dicen que fue para salvar la vida pero no nos dan la potestad de decidir sobre nuestra vida y la gente está diciendo en la última reunión en Puerto Valdivia: es que nos tratan como marranos, nos tratan como a otras especies porque deciden en qué cocheras ponernos, porque ahora están decidiendo cómo van a ser las casas para reconstruir. Ni siquiera se pregunta cómo quiere su casa, según sus formas de vida, según lo que consideran del espacio que habitan y hoy se les impone, o pretenden imponérseles, una casa en donde vivir, qué comer, qué hacer, de qué vivir, y eso es una transformación total de la sociedad. Es como si a ustedes hoy les dijeran no pueden ser estudiantes de la Santo Tomás sino que todos tienen que ser pescadores y pescadoras y ustedes queriendo ser otra cosa, estudiantes, profesores, quieren estar aquí y otra persona, porque 
es muy poderosa, una empresa, les dice: a partir de hoy usted va a ser esto, no eso que usted decidió, sino lo que yo decida que usted va a hacer, porque yo soy el que mando en el territorio. Entonces, la prioridad para establecer compensaciones, reparaciones, es construir colectiva y participativamente y para ello que se nos dé la voz a los que nos hemos opuesto, a los que no estamos de acuerdo, porque en eso también ha habido exclusión, nos dicen que no podemos opinar, que no podemos disentir, ni estar organizados para decir que no queremos esto y que no queremos que decidan por nosotros.

Víctor Julio Atencio García: desde mi experiencia sobre impactos de hidroeléctricas sobre recurso pesquero, [puedo decir que] hay dos momentos importantes con el proyecto que nos ocupa. Este es un proyecto de un poco más de veinticinco años, cuando se empezó a hablar en el país, en el año 1974, de este tipo de proyectos. Entonces se determinó que su viabilidad estaba en el sitio conocido como Ituango y las obras de construcción iniciaron en el 2010 y paradójicamente en el 2018 debería iniciar a dar los beneficios propios de la hidroeléctrica. Sobre estos proyectos, la sociedad debe tener claro que tienen factores que benefician y factores que afectan. En este modelo de desarrollo de generar energía a través de hidroeléctricas, son proyectos que impactan bastante al medio ambiente, específicamente al recurso pesquero. En general, en estos proyectos, entre más grande es el área de embalsamiento, mayores son los impactos. Nosotros tenemos un ejemplo de que el primer impacto es, desde que inician sus obras, la fragmentación del río, se pierde la continuidad, el embalse empieza a actuar como una trampa de sedimentos y afecta tanto a las comunidades arriba del proyecto como a las de abajo. Estoy hablando de comunidades de peces, los peces tienen unos efectos sociales muy importantes porque la mayoría de las comunidades que viven de la pesca resuelven su seguridad alimentaria, sus ingresos, a partir de la pesca, entonces, comienza a haber un efecto social, económico y por supuesto político. Una vez que se fragmenta el río, se pierde continuidad en la producción de las especies de mayor interés comercial para las pesquerías, para las comunidades, como son las especies migratorias, las especies que su dinámica poblacional, su ciclo reproductivo depende de migraciones. Estos proyectos interrumpen esos procesos de reproducción, se interrumpe la dinámica poblacional, eso son impactos que todos los proyectos hidroeléctricos deberían calcular y mitigar. El problema con Hidroituango es que por algunas consideraciones de localización, de ingeniería, el proyecto no ha podido estabilizarse y lo que han hecho los manejos posteriores es potencializar esos impactos, como el año 2018 en donde se han tomado una serie de medidas que culminaron con el desecamiento del Río Cauca. Entonces tenemos un impacto que hay que mitigar y compensar. En esta fase, lo que hay que hacer es evaluar los impactos en el corto, mediano y largo plazo, que se han agravado y se han potenciado con el manejo que se le ha dado a la hidroeléctrica para estabilizarla. Yo, por las especies que vi en las imágenes, creo que el área que sufrió mayor desecamiento fue la de maduración y desove del bagre. Los peces pequeños que se ven allí, por el hecho de ser pequeños, no es que no tengan importancia pues son la comida de otros peces en la cadena trófica, pero lo que presumo es que hay una afectación muy importante que va a desestabilizar las comunidades de los grandes peces carnívoros, incluidos los bagres, y de los 
forrajeros. Creo que debemos seguir identificando los impactos, que aún no estamos en etapa de tomar medidas compensatorias, para el caso particular del recurso pesquero, porque pueden ser medidas a la ligera, primero debemos saber qué se está afectando. Con las herramientas que nos permite a nosotros la ciencia, establecer los impactos, por supuesto hay unos daños que van a tardar en recuperarse en el corto, el mediano y el largo plazo, en eso no hay discusión. Pero yo creo que estamos todavía en esta etapa de valoración de los daños sobre el recurso pesquero, que se han potencializado por los últimos manejos que ha hecho la hidroeléctrica.

Luz Fernanda Jiménez: hablando de los impactos en la hidro, ahora se requiere una atención rápida y nosotros estamos, desde varios grupos de investigación, analizando un poco como son los cambios que genera esta situación tan compleja a las especies de peces, y podemos aventurarnos a decir algunas estrategias que puede desarrollar la empresa y la autoridad ambiental, teniendo en cuenta escenarios como el de la semana pasada, con un momento de sequía extrema en el río Cauca. En este caso, lo primero que se sugiere ver es la situación de las especies y acompañar a la comunidad y a la empresa para dar una posible solución en torno a esta discusión. A su vez, realizar un análisis con toda la información que ha venido recogiendo la empresa para proponer estrategias al bajo Cauca un poco más acertadas y ajustadas. En término de compensaciones, ya hablamos que, una vez que se permita que el proyecto continúe y el embalse empiece a generar, lo primero que hace un embalse es el régimen hidrológico y la conectividad entre los sistemas acuáticos sobre todo en la zona baja. Entonces, es muy importante que se empiecen a considerar acciones de recuperación de las zonas bajas de la conectividad de todos los momentos del ciclo climático en la cuenca. También acompañar a los pescadores desde sus prácticas pesqueras porque el río va a cambiar y va a tener menor transferencia. También apoyarlos en temas productivos que les dé una alternativa diferente a la captura, no es que dejen de pescar, sino encontrar otras oportunidades de mejorar su calidad de vida.

Hernán Sánchez Cruz: vengo en representación de la empresa EPM para contarles que hay desinformación al hablar de las condiciones, los profesionales y la honestidad con que se han llevado a cabo las acciones. Estoy de acuerdo con el planteamiento de la Dra. Isabel Cristina, y así se lo planteé en alguna ocasión cuando estuve hablando con las comunidades de Puerto Valdivia, que nosotros no podemos llegar con una tarjeta sacada de un bolsillo para decirle a las comunidades cuáles son las medidas de manejo y volverlos de la noche a la mañana vendedores de carne o de pan, sino que las medidas compensatorias se construyen de manera conjunta. Es decir, la empresa preocupada por el recurso hídrico desde el punto de vista biótico, dado que cuando se construye una presa obviamente el impacto más crítico es la ruptura de la subienda por esa nueva barrera. Desde el año 2010 la empresa viene desarrollando monitoreos y en este momento tenemos cincuenta y un estaciones que van desde Bolombolo hasta la desembocadura del río Magdalena y es importante que sepan que esos monitoreos permitieron establecer que entre el río Ituango y Puerto Valdivia, que se encuentra más o menos a $38 \mathrm{~km}$ del sitio de presa, se encuentran veintiséis raudales que ya rompieron la subienda, y esto hace que no se vea venta de pescado en Santa Fe de Antio- 
quia, por ejemplo y con esta valoración y en condición normal los bagres llegan a $20 \mathrm{~km}$ de Puerto Valdivia, cuando se han dado esas fundiciones de barro y caudales.

Otro aspecto importante que mencionaba el Dr. Víctor Julio Atencio es que en $15 \mathrm{~km}$ el río Cauca pasa por más de 180 municipios, entonces aquí se recoge la basura de todos estos municipios. Son millones de personas que votan los residuos y las aguas residuales que llega en muchos casos sin tratamiento. Por ejemplo, en la planta de Cali tratan el $60 \%$ de las aguas. Hay que mirar que el botadero Navarro expulsaba los lixiviados que generaban directamente al río, aunque hace unos años ya no sucede.

Orlando Rangel: todos somos conscientes de que necesitamos transformar y utilizar parte de los recursos naturales no renovables pero también tenemos que ser conscientes de la magnitud del impacto, ya que en su historia el hombre ha utilizado recursos, pero es que aquí estamos ante el desborde, la ambición desmedida. Utilizar el agua como recurso, se hace desde hace milenios en las comunidades rurales, las plantas. Pero este Frankestein demuestra la falta de control y aquí hay una cosa que es supremamente importante, el río Cauca ya no va a ser el mismo de antes de la intervención y esto ni por más que lo digan los súper expertos, no es posible, vamos a tener aguas abajo y aguas arriba un río totalmente transformado y eso implica unas alteraciones biológicas y ecológicas muy fuertes, que en el término medio de cincuenta años de la represa quizá no vamos a volver a tener. En la historia geológica nuestra hay una cosa que hay que entender, si no cesa el efecto transformador, se acaba y nos extinguimos. Si los cambios de temperatura de los últimos 110 mil años no hubieran cesado hace 13 o 14 mil años, estaríamos extintos, porque la masa de hielo nos hubiera cubierto a todos, esto cambió porque cesó el efecto. Si la elevación de las cordilleras no hubiera parado pues tendríamos cataclismos pero el efecto transformador cesó y entonces el sistema se pudo recuperar, pero en el caso de Hidroituango no porque aquí tenemos una represa que no cesa.

\section{Segunda pregunta}

¿Qué acciones puntuales pueden llevarse a cabo para disminuir la afectación social y económica de las cerca de 35.000 personas afectadas directamente por el proyecto, que han perdido su principal medio de subsistencia?

Víctor Julio Atencio García: este es un proceso bastante complejo en el sentido de que las acciones y las compensaciones que se vayan a realizar se tienen que hacer en los ejes que afectan el proyecto, en el eje social, en el ambiental y en el económico. Yo, a partir de mi experiencia acerca de los peces y de las poblaciones de pescadores, creo que va a haber una afectación sobre las comunidades pues su cultura y sus ingresos dependen de la pesca. Esas compensaciones tienen que ver con el corto, el mediano y el largo plazo porque en esa misma escala de tiempo están los impactos, las comunidades comen todos los días y hay que resolver su manutención en el día a día y tiene que haber programas en el mediano y el largo plazo. Ya la profesora Luz Fernanda mencionó algunos, de recuperación de las áreas y de recuperación de la dinámica de la población de peces para que la pesca vuelva a ser una posibilidad de manutención de las familias. Entonces, tenemos que ver qué compensar para enfrentar los problemas porque la gente que 
vive de la pesca empezó a ver afectados sus ingresos y su seguridad alimentaria. En el día a día en otras partes, los pescadores van y pescan, una parte va para su seguridad alimentaria y otra para la comercialización, pero en esa región eso está completamente fracturado. Estoy de acuerdo con la doctora Isabel Cristina que esto tiene que ser concertado, a nadie le gusta que se le imponga un modelo de vida y voy a traer a colación aquí el caso de las comunidades que son recolectoras y pasan a modelos productivos; el esquema mental de ellos no está en producir porque son recolectores ancestrales. Entonces hay que hacer toda una transición desde lo social para que el esquema productor sea asimilado por esas comunidades, caso contrario, esos planes productivos ninguno dará resultado.

Isabel Cristina Zuleta: yo creo que realmente no hay posibilidad ni de compensación, ni de acciones puntuales, ni de disminuir la afectación, si el daño sigue continuado. Lo que hay es que cesar el daño, porque, no es posible que a mí me pregunten cómo me van a reponer el daño que me hicieron si todos los días me siguen dañando. Primero hay que parar esta situación porque el principal problema hoy es que se destruyó el proyecto de vida, no se sabe hacia dónde dirigir la vida, no se sabe qué va a pasar mañana. Entonces, un problema social de zozobra permanente, de angustia, de no saber para dónde vamos como comunidad, miles y miles de personas, no se puede recomponer con dar un mercado. Primero se tiene que cesar el daño. Si no cesa el daño, no hay manera de recomponer nada, ni socialmente, ni culturalmente. Primero tiene que cesar el daño, y el daño es la amenaza y la amenaza es la obra. Primero nos tienen que decir qué es lo que va apasar con esa obra y, por supuesto, no sólo pongo en duda la honestidad de EPM, sino que lo hemos dicho con toda claridad: es una empresa criminal porque no se le puede llamar de otra manera a una empresa que destruye el proyecto de vida, no sólo del pasado, sino qué va a pasar con el proyecto de vida de miles de personas. $Y$, en ese sentido, a uno si le llama la atención cómo se le da vueltas. Nos han querido montar en la idea de que la única manera de estar bien es si se salva el proyecto, si el proyecto avanza. La única manera de que nosotros podamos estar bien es que no haya más amenaza, es decir, que no haya más proyecto. Que se desmantele de manera controla$\mathrm{da}$, que primero se liberen esas aguas, que se liberen esos sedimentos que son parte del ecosistema, fundamental para el ecosistema y que realmente se libere porque es cierto, tardarán muchos años, pero va a tardar más mientras más daño haya. Y el daño es continuado todos los días.

En términos económicos, nosotros tenemos que decirles que, primero, hay un sujeto ético, y lo decía el señor de EPM, él estuvo en Puerto Valdivia, pero no tiene posibilidad de diálogo EPM con la comunidad, porque éticamente no es capaz de pararse en frente, la comunidad está furiosa, está molesta y con toda la razón. Ahí no hay posibilidades de diálogo, porque entonces nos montamos en la película de que con todo el mundo se puede conversar y no, no todos podemos conversar. Es que yo que soy víctima del conflicto armado, yo no me puedo sentar con mi victimario, ni puedo esperar que mi victimario me dé las salidas. Debe haber un sujeto ético y para eso delegamos en la justicia, y para eso delegamos en otros que tienen esa potestad, esa altura ética de no haberme dañado, para que me acompañen en ese proceso de reconstrucción, pero yo no le pue- 
do pedir al mismo que me dañó, que venga y construya conmigo. Porque ahí no hay posibilidades, tiene que haber otro sujeto ético y ese no es la empresa EPM, no es la gobernación y no son todos los interesados en la obra. Nosotros como comunidades estamos buscando ese otro sujeto ético que nos ayude a reconstruir un proyecto de vida que ha sido fracturado por una empresa y por unos intereses económicos.

Luz Fernanda Jiménez Segura: reducir la afectación depende de si se remueve el embalse. Pero yo me voy a referir al tema de los peces y los pescadores. El tema de los peces y los pescadores es que es más un problema de cuenca y no sólo lo de los embalses, es un problema de avance de la frontera agrícola, de la minería, de la contaminación del agua, entonces en el caso de que removamos el embalse, el río fluirá, digamos que en términos hidrológicos mantendrá las condiciones pero en términos de las otras amenazas que son las que también afectan las poblaciones y a la población de la pesca, se van a mantener, salvo que las autoridades ambientales hagan algo para controlarlas. Y en el caso de que el proyecto se mantenga, que el embalse continúe, que se empiece a generar energía, entonces retomar todo lo que hablé respecto de cuáles serían las estrategias de manejo. Primer escenario, habría que realizar acciones para recuperar el río porque los peces y la producción de los pescadores no solamente son un problema de los embalses sino de desarrollo acuícola de la cuenca, de cómo manejamos la cuenca. En caso de mantener el embalse, básicamente es asegurar las condiciones hidrológicas, de conectividad lateral, de descargue, según las condiciones técnicas de la presa y de cómo opera para garantizar el aporte de nutrientes aguas abajo. Tenemos dos escenarios, cuál de ellos es el mejor lo definirán las autoridades ambientales.

Orlando Rangel: es muy difícil, con todo respeto, pretender cambiar el comportamiento mundial, estamos en la globalización, yo siempre me he opuesto a muchas cosas de la globalización, del neoliberalismo pero desafortunadamente a veces es muy difícil. ¿Por qué estamos en lo que estamos? Porque en el 91 vivimos una crisis muy fuerte ¿se acuerdan de la hora Gaviria, del apagón? Ahí los gurús de la economía dijeron: hay que incrementar la generación hidroeléctrica. Y mucha gente dice: si, es muy bueno porque solamente afecta a los ríos y entonces ¿qué pasa? No pasa nada, porque ese es el imaginario de la gente, que no pasa nada, convertir un río en un lago, eso no pasa nada. Y así lo han vendido. Pero la gente que está aumentando su nivel intelectual está entendiendo que si pasa y que pasan cosas muy graves. Entonces, se construyeron las represas, pero ¿dónde se construyeron? En donde lo definieron los intereses políticos. Miren, yo vivo insistiendo en que no engañen a la gente, diciéndole que en diciembre viene el niño y el único que viene es el niño Dios para los católicos, pero eso de asustar con la temporada sin lluvias, ese es el comportamiento normal, casi todo el país es bimodal de transición, dos épocas de lluvia, dos épocas secas, pero las represas se hicieron en los sitios con intereses políticos. Si a mí me hubieran preguntado les hubiera dicho: busquen un sitio donde no haya temporada de sequía.

Tenemos el país más rico del mundo en biodiversidad y en paisajes. Sí, es necesario intervenir, es indudable, no podemos seguir en la época de hace quinientos años, pero tiene que 
haber una responsabilidad y las autoridades gubernamentales tienen que escucharnos, el problema es que no nos escuchan. Entonces, el asunto no es que hay que desmantelar y ya, no. Hay es que mirar cómo es el asunto. ¿Por qué se permitió este Frankenstein, no era suficiente? no... es que Hidroituango tenía que ser cuatro veces El Quimbo. El Quimbo suscitó toda la discusión del caso, pero aquí nada pasa. Entonces no, nosotros tenemos que ser más poderosos. Miren, cuando uno se pone a mirar las cifras de Hidroituango uno entiende porqué se caen los puentes y porqué se caen los edificios, porque la ambición, como dice el dicho, rompe el saco. Es decir, cuando uno se imagina $70 \mathrm{~km}$ intervenidos, un área de represa de 8.500 a 9.000 hectáreas, una profundidad de 80 a 100 metros, uno dice: verdaderamente no hay temor de Dios, no hay temor de un todopoderoso, según la cultura, según la tradición, o no hay temor de la sociedad y es jugar a ser todopoderoso.

Entonces, aquí lo que tenemos es que serenarnos, contarnos las cosas, escucharnos y entre todos buscar. Nosotros tenemos ejemplos muy clásicos que nos pueden servir. Yo le pregunto al profesor Atencio qué ha pasado en Córdoba. Nosotros trabajamos diez años en Córdoba y me tocó dos movimientos sociales que fueron muy fuertes, que casi paralizan al país. Cuando ya las repoblaciones de peces se acaban, las poblaciones le dicen a uno: doctor yo no quiero comer pasta, yo quiero es mi bocachico. ¿Qué hacen esas poblaciones?, las poblaciones siempre vivieron del Sinú. Una mitigación, va a ser una aspirina para una neumonía y lo importante es que el país tome conciencia de que no se pueden seguir permitiendo estos Frankenstein, estos megaproyectos, por favor. $\mathrm{Y}$ que tenemos que tener cuentas claras, cuánta es la energía que necesitamos, cómo nos está llegando, porque ya nos van a meter el fracking también.

Hernán Sánchez Cruz: cuando estaba hablando anteriormente, se perdió la conexión con Bogotá y quiero ser insistente en los estudios que hemos hecho para devolver la condición de la subienda que es el aspecto de interés en el río Cauca y reitero, entre la presa algunos raudales, ya de manera natural rompieron la subienda.

Hay otro aspecto fundamental. Esta es la primera hidroeléctrica que tiene en su licencia ambiental una regla de operación. El proyecto tiene que simular las condiciones de los caudales que entran, se tienen que estar restituyendo aguas abajo. Esa medida del manejo la tuvo que implementar en su momento también el proyecto hidroeléctrico de Isagen, ellos llenan una rampa que evita que no haya esas fluctuaciones abruptas en raudales en horas pico cuando se requiere mucha energía y se tiene que soltar toda el agua para inundar el río y en horas valle se seca y se dan las condiciones rápidas de inundación y sequía. Este proyecto tiene esa connotación de que se cuenta con una regla de operación. Ahorita que se mostraba en la condición del cierre de la compuerta que se abrió en la tragedia ambiental, ahí clamo para que nos escuchen, nos pongan cuidado, yo soy una persona honesta y también los estudiantes que fueron estar pendientes, que sepan también la verdad. Se murieron 85.000 peces, rescatamos 480.000 , esos 85.248 peces que murieron correspondieron a 878 kilos. En el río Cauca se pescan al año 270 toneladas. Miremos realmente cuál fue el impacto, porqué se habla de la tragedia ambiental. Allá iban los noticieros, pero no mostraban el cauce 
del río, sino donde quedaron los peces atrapados. Aquí la empresa contrató 748 pescadores de la zona para tomar todas las medidas para rescatar los peces. Entonces es bueno que se tenga este contexto. En este proyecto no son $10.000,8.000$, son 4.000 hectáreas que se inundan y esas 4.000 hectáreas, el proyecto tiene que compensarlas con más de 17.000 hectáreas. Con la franja de protección del embalse que es un kilómetro a la redonda, esto llegaría a completar más de 18.000 hectáreas de bosque. Incluso, ya empezamos procesos de restauración ecológica para que se haga de una manera bien hecha y devolver bosques en áreas que eran potreros, zonas de cultivos ilícitos, en áreas que fueron al mismo tiempo de la agricultura y de la minería. Entonces, es bueno que se tenga en cuenta también ese contexto, los beneficios que van a tener las transferencias de dinero que van a recibir los municipios que tienen influencia en la primera área donde se localiza el embalse.

\section{Tercera pregunta}

Tenemos un dato que, en concordancia con el informe entregado por la Contraloría General de la República, dice que, de los 35 hallazgos, 29 tuvieron presunta incidencia disciplinaria y 8 penales, ¿Usted cree que la crisis de Hidroituango se debe más a las fallas de control en el cumplimiento de las normas técnicas, o la falta de capacidad de EPM y las demás empresas involucradas en desarrollar este tipo de megaproyecto?

Hernán Sánchez Cruz: como toda la opinión pública sabe, pues están realizando investigaciones exhaustivas por parte de las entidades de control. Este proyecto lleva construyéndose desde 2011, esperamos que salgan los resultados de las investigaciones.
Yo, aquí quiero contarles que Empresas Públicas de Medellín es una empresa colombiana, del municipio de Medellín. Considero que no es una empresa criminal, somos gente honesta que, como ustedes, diariamente salimos a ganarnos nuestro salario desde el punto de vista profesional con toda la honestidad del caso y haciendo lo mejor, como me enseñó la Universidad Nacional el tiempo que estudié allá. Esa empresa fue creada en el año 55, lleva construidas 26 centrales hidroeléctricas, una central eólica y una central térmica. Considero que eso le da toda la idoneidad a la empresa, algo falló, alguien determinará cuál fue la falla y de quién. Por otro lado están las empresas que contrató el consorcio de obras municipales que se llama consorcio CCC Ituango, integrado por las firmas Camargo Correa, Coninsa-Ramón H y Constructora Conconcreto. Camargo Correa es una de las empresas más reconocidas a nivel internacional, es brasilera. Están las firmas Integral e Indetec que realizan funciones de asesoría e interventoría, empresas que cuentan con toda la experiencia. Alguien determinará de quién fue la culpa, pero no fue en ningún momento algo malintencionado.

Orlando Rangel: yo he dicho que todos tenemos parte de la culpa. En Colombia, desafortunadamente, los controles no funcionan y no funcionan porque cada cuatro años todo cambia, no hay continuidad, y cambia para que se siga la propuesta de quien en ese momento detenta el poder, es por eso muy difícil solucionarlo. Aquí faltó el control desde un principio. Todos nosotros, los académicos, nadie, se interesó. Uno piensa que en quien se ha delegado, va a cumplir. Nosotros, por ejemplo, tenemos que pedir permiso para ir a un sitio, para conectar una planta, para conectar un aparato y nos hacen llenar montones de papeles, pero 
nosotros tenemos un impacto mínimo. Uno se imagina que es lo mismo en una cosa de estas, pero según los resultados no. Entonces, aquí ha habido falta de control esencial por parte de quien tiene la representación de la sociedad que son las autoridades ambientales. Miren, lo dejamos para el final, pero esto, son pañitos de agua tibia ante la magnitud de los cambios que se generaron, que se van a generar y por supuesto, nosotros no tenemos la verdad para decir qué desapareció aquí, hay que hacer unos estudios para determinar cómo se afectaron las cadenas tróficas, etc. Las autoridades y quienes impulsaron la idea pecaron de soberbia y de ambición. Aquí sencillamente, son esas propuestas de llegar al $20 \%$ de producción de energía, pero ¿realmente necesitamos eso? O será que los generadores convirtieron esto en un negocio. Un bien de la nación que son los ríos, un bien de la nación que son los hidrocarburos, los aprovecha un sector con unos réditos y a nosotros ¿qué nos dejan?, unos pasivos ambientales que son muy grandes. Ojalá que seamos Cassandras, porque lo que se viene es inconmensurable, 78 kilómetros de afectación van a ser una cosa apocalíptica.

Víctor Julio Atencio García: realmente, me gustaría tener la tranquilidad pero, por supuesto, por las dimensiones de la situación, por la gravedad y por el orden de afectación hay que dejar que los organismos de control y de fiscalización hagan su tarea y, ojalá lo más pronto posible, determinen los grados de responsabilidad. Yo quiero aprovechar este espacio para comentar dos cosas. Uno, tenemos que revisar el modelo de desarrollo para la generación de energía en el país, el 70\% de esta depende de las hidroeléctricas. Colombia optó por este modelo que tiene un alto impacto ambiental, a mayor represamiento, mayor impac- to ambiental. Existen otras formas de generación de energía que el país tiene que comenzar a considerar como una ruta para evitar este tipo de conflictos porque estamos afectando un bien común que es de todos y que, necesariamente, nos va a afectar a todos.

Lo otro es el caso del río Sinú, una hidroeléctrica un poco más pequeña, el embalse es de 8.000 hc, la generación es de $400 \mathrm{mw}$ frente a 2.400 que es el caso de Hidroituango. Por supuesto, estas obras tienen una afectación desde su planificación, o sea cuando comienza a intervenirse el río, hasta su vida útil, entre cincuenta y sesenta años, como se mencionó. Por supuesto que el río no va a ser el mismo, pero recuerden que, en el caso de los peces, se trata de organismos vivos que tienen capacidad de resiliencia para enfrentar la situación. Lo que hemos visto en el río Sinú son periodos críticos, se afectó la comunidad de pescadores tanto que prácticamente desaparecieron, más, sin embargo, el proceso de manejo, nosotros como universidad, acompañamos, orientamos, asesoramos a la hidroeléctrica sobre cómo deben hacer esos manejos para mitigar esos impactos. Y después de 18, 19 años, hemos visto una recuperación, o sea, ya tenemos el primer registro después de 18, 19 años de que hubo una recuperación de la dinámica reproductiva de los peces en el río Sinú a como era antes de que estuviera la hidroeléctrica. Cada caso es necesario estudiarlo, en todo caso recuerden que el recurso pesquero es algo que está asociado a la seguridad alimentaria en las regiones, si afectamos la seguridad alimentaria, afectando la vida de las poblaciones.

Luz Fernanda Jiménez Segura: en consonancia con lo que se mencionaba acá, nosotros no tenemos los elementos para decir quién es res- 
ponsable y quién no pero tiene mucha razón el profesor Rangel de que todos somos responsables, desde el ciudadano de a pie que cada vez más depende de la energía eléctrica para su bienestar, desde la autoridad ambiental que puede tener algunas fallas en el acompañamiento, desde las mismas políticas de Estado porque no existe un órgano que permita supervisar o aprobar las especificaciones de construcción, desde el ANLA que aprueba los estudios de impacto ambiental pero no hay una entidad del Estado que apruebe los diseños de construcción, o la ubicación de la planta, digamos que hay fallas por todo lado. Dentro del sistema ambiental hay un pacto que es importante resaltar y es que el Estado ha delegado en las empresas la construcción del inventario de la biodiversidad y, además, les ha delegado el mencionar los impactos ambientales y proponer los manejos. Eso no puede ser posible, el Estado es quien debe conocer la biodiversidad antes de que una empresa defina dónde va a poner una presa o una mina o un cultivo de palma. $Y$ en el momento en que una empresa le solicite un recurso el Estado debe evaluar el impacto y definir las acciones de compensación y de mitigación. Eso no lo pueden hacer las empresas. En primera instancia, el nivel de profundidad que tiene el impacto ambiental con el cual se toman las decisiones. En ese caso hay dos momentos: uno es que el estudio de impacto ambiental lo hace la empresa, lo construye la empresa y lo evalúa la autoridad ambiental, eso no puede ser así. Y en segunda instancia la profundidad de los estudios en donde hay varias etapas: prefactibilidad, factibilidad, diseño, pero la mayor profundidad se espera solamente en diseño, no en el estudio de alternativas donde debería estar, para que desde ese momento la empresa sepa si es posible o no es posible hacer una iniciativa ahí de cualquiera que sea su actividad económica, eso es como mejor.

Isabel Cristina Zuleta: lo primero es definir qué es una crisis, porque entonces, para entender como una crisis el proyecto en sí mismo, porque hemos venido de crisis en crisis. A mí me llama la atención escuchar como cada vez que habla EPM nombra una fecha distinta. Hace apenas dos años decía que las obras habían empezado en el año 2009 y hoy vengo a escuchar que dicen que en el 2011. Hace apenas dos meses decían que en 2010, que eran los datos oficiales que presentó la universidad. Y porqué eso es importante, porque juegan con los datos para poder manejar la información. Si sólo es la fecha, yo doy fe de que empezó en el 2009 porque yo estaba ahí, y empezaron a abrir las carreteras en el 2009, no en el 2010, ni en el 2011. Y eso es un dato supremamente importante porque en la medida que van extendiendo su deseo de salvar la obra, van necesitando más tiempo y, para eso, van necesitando más plata. Entonces necesitan reducir la percepción de que esto no ha sido eterno como lo ha sido para nosotros. Por eso lo llamamos: Hidroituango, un riesgo eterno. Hasta que no se nos dé fecha final, no podemos nosotros decir que hay posibilidades éticas en este país. Hay posibilidades siquiera de resarcir el daño moral que hemos tenido por todas las víctimas que quedaron allí, debajo de esas aguas. Entonces, qué decimos nosotros, la crisis es en todos los sentidos. Es ecológica, por supuesto, lo que se está analizando hoy. Pero es una crisis ética y es una crisis moral y es una crisis espiritual, porque es que la dimensión de la muerte que no la puede tratar una empresa, no la puede tratar porque está en otra esfera, no le corresponde ni siquiera tratarla, es una dimensión fundamental para el proyecto hidroeléc- 
trico Hidroituango porque se asentó sobre una zona de muerte. Nosotros hemos documentado con los datos oficiales 136 masacres, más de 2.000 desaparecidos y eso es una dimensión humana que tiene que ser valorada, ¿quién lo va a valorar, la empresa? Como lo decía la profesora, no puede, no tiene esa potestad y no la debería tener nunca, aunque hoy se le ha dado la potestad de exhumar y ha licitado y hasta se privatiza el hecho de meterse con los muertos y de exhumar cuerpos. Eso es aterrador para una sociedad, entonces el llamado que uno haría en estas reflexiones es: el movimiento Ríos Vivos Antioquia, que es un movimiento de comunidades afectadas del norte, occidente y bajo Cauca, no surgimos porque quisimos, porque tan bueno salir a protestar, porque tan bueno ser activista, surgimos porque nos tocó, porque no aguantamos la indignación, porque no sabemos qué más hacer, porque no sabemos a dónde acudir, porque se nos acabaron las herramientas, porque hicimos denuncias, desde el 2008 las estamos haciendo y no ha habido, como dice el doctor Rangel, una sociedad que escuche, pero esa sociedad es la que nos dice que nos tenemos que sacrificar en pos del desarrollo de otros. Hoy en Colombia y en el mundo se están sacrificando las comunidades rurales y nosotros venimos a decirles, entonces ustedes van a seguir permitiendo que se nos sacrifique, se nos sacrifique a nosotros, se sacrifique a las comunidades en la Guajira, por su comodidad, por sus intereses. ¿Ustedes hacen parte de eso, quién hace parte de eso?, porque es cierto, el que no ha dicho nada también se convierte en cómplice.

De esa masacre, no fueron 85.000 peces y el dato es importante, empezaron a decir 50.000 , ya van en 85.000 , ustedes tenían el dato de 70.000. No, no fueron esos, fueron muchos más. Decidieron que no se rescataban peces en la noche y todos los que conocemos de ríos sabemos que se pesca es en la noche. ¿Por qué no se rescataba en la noche? Nosotros, sólo nosotros, comunidades pesqueras y organizadas, rescatamos más de 10.000, entonces no fueron 85.000 , con escasos recursos porque no tenemos nada. Y ese dato es importante, porque no es que se murieron, como lo quieren hacer ver, es que los asesinaron, porque fue planeado, fue adrede. En este país tenemos una autoridad ambiental de adorno porque ni siquiera le avisaron, primero nos dimos cuenta nosotros, que ellos. $\mathrm{Y}$ avisaron dizque de emergencia por la noche, cuando nosotros ya sabíamos que iban a cerrar las compuertas y lo pueden ver en nuestras redes sociales, porque nos avisaron que se iba a ir el agua y que no se sabía cuándo iba a volver. Ese fue el aviso de la mortandad. ¿Por qué? porque la muerte también nos iba a llegar, ¡ah, no!, el agua para ustedes llega cuando EPM diga. Es el control, control de la vida social.

Y es muy importante que aquí los jóvenes sepan que definitivamente hay que cambiar el modelo. Hidroituango no se necesitaba, Hidroituango no es un proyecto técnico, lo he escuchado de los mismos funcionarios, avergonzados, porque los hay, de EPM, que sienten vergüenza de lo que ha sucedido. Y nos han dicho, EPM nunca quiso Hidroituango porque sabía que Hidroituango era inviable técnica y ambientalmente. El problema es que Hidroituango es un proyecto político, no es un proyecto técnico. Y como es un proyecto político tenía que salir adelante, tenía que salir adelante porque unos poderosos tomaron esa decisión. Este es el cuestionamiento a esta sociedad que permite ese tipo de decisiones. Un proyecto político, un proyecto que rompe, no sólo con 
la dinámica ecológica sino con la dinámica social y un proyecto en el que nosotros no vemos futuro si nos dejan esa bomba de tiempo ahí. Y vemos que Colombia como sociedad tiene que pensarse si va a seguir sacrificando a las comunidades rurales, porque aquí en la ciudad no se produce la comida, porque tenemos que comer todos los días, y porque es allá donde se reproduce la vida y eso es lo que hay que poner en la balanza. En este momento nosotros estamos sufriendo una crisis, una hambruna gigantesca, pero hay un dolor también gigante por el río. Yo quiero finalizar agradeciéndoles por esas manifestaciones de cariño que tienen aquí a la entrada al auditorio, porque lo llenan a uno de emoción, porque esto puede ser un asunto muy técnico en todas sus dimensiones, pero, realmente, para nosotros es un asunto espiritual, es un asunto de humanidad, es un asunto de dolor y es un asunto de dignidad. $Y$ esas son las expresiones, cuando uno deja salir ese amor que tiene hacia el medio que lo rodea puede conectarse, si no, simplemente va a especular, porque realmente lo que puede mover y transformar una sociedad son sus sentimientos, son sus emociones, no la técnica y no la ciencia. Muchas gracias.

\section{Cuarta pregunta}

¿Cómo la crisis de Hidroituango afecta al

colombiano de a pie, al que ve todo por la $\mathrm{TV}$, pero no vive en los municipios afectados?

Jorge Sánchez: yo creo que el colombiano de Leticia, de la costa, de Tunja va a percibir esto y va a ver verdaderamente afectada su confianza. Se afecta la confianza de nosotros mismos como personas de a pie, cada vez se va perdiendo más y más en nuestro país. Ya hoy en día se nos viene el fracking como dice el Dr.
Rangel, ya tenemos desconfianza; van a construir el metro de Bogotá, ya estamos diciendo cuánta plata se van a robar; van a construir un aeropuerto o una carretera que la necesita el país, la famosa Ruta del Sol que era la ruta del país que iba a conectar a Bogotá con Santa Marta, ya vemos todo lo que ha pasado con la segunda fase. Entonces lo que estamos viendo es una pérdida de valores, es una desconfianza de todo y ahí es donde nosotros tenemos que jugar un papel fundamental. Una desconfianza con nuestras autoridades, la corrupción que verdaderamente está desbordando la desconfianza por los conocimientos técnicos que aprendemos en las universidades, pero, muchas veces, al ingresar a una empresa nos exigen lo que tenemos que hacer, lo que tenemos que decir y nosotros no podemos opinar y sentar nuestra posición con contundencia técnica porque inmediatamente nos despiden. Entonces, yo pienso que esto es lo que está sufriendo el país, la desconfianza.

Otro tema importante que tocaron aquí, es el de la autoridad ambiental, la que da la licencia ambiental. ¿Cómo es posible que el presidente nombra al ministro de Medio Ambiente y el Ministro del Medio Ambiente nombra al director del ANLA... pues cuál seguridad de interventoría va a haber para una obra que viene impuesta desde el gobierno? La autoridad ambiental de este país tiene que estar en manos autónomas, totalmente independientes, por ejemplo en las universidades, en la academia, en las facultades de ingeniería ambiental, con sus especializaciones y sus maestrías, aquí tiene que estar la autoridad ambiental, la que debe señalar lo que no se está cumpliendo, hay que parar esto porque nosotros a veces hablamos que vamos a construir sobre nuestras experiencias pero siempre estamos viendo que 
muchas experiencias en este país verdaderamente son negativas, entonces yo pienso que estamos perdiendo la confianza y tenemos que volver a recuperarla.

Luz Fernanda Jiménez: esta crisis debemos ponerla como en dos contextos, el primero con embalse y el segundo sin embalse. Con embalse algunas personas lo quieren y sin embalse otras personas también lo quieren. Entonces con embalse: básicamente lo que tenemos que tener claro nosotros es que si no hubiera redes sociales no estaríamos enterados de lo que está sucediendo allá o de lo que sucede con la mortalidad de peces en la Ciénaga. Entonces el ciudadano de a pie no estaría informado de lo que está sucediendo. Con embalse, básicamente lo que va a suceder es que si no se realizan las actividades para buscar que la conectividad fluvial se restaure entonces vamos a dejar de ver peces como el bocachico o el bagre, ese sería el destino final y empezaríamos a utilizar especies exóticas como la tilapia. Sin embalse podríamos adelantar algo de la renovación de las poblaciones de peces desde siempre y cuando las autoridades ambientales controlen las otras afectaciones que vienen sufriendo los peces. Y también tendríamos que presionar para que el Ministerio de Minas y Energía promueva la generación u obtención de la energía eléctrica desde otras fuentes, porque el ciudadano de a pie si se vería muy afectado cuando se le va la energía, entonces habría que fortalecer la energía para sopesar la ausencia de un proyecto como Hidroituango pero pensando no para el año entrante ni para en cinco años sino a largo plazo.

Víctor Julio Atencio García: evidentemente creo que sin mayor profundidad las consecuencias de esta situación generadas por la construcción de Hidroituango van a ser unas consecuencias que están afectando a todo el país. Las comunidades del bajo Magdalena ya se vieron afectadas y por supuesto esto ya ha generado sobrecostos que al final los terminamos pagando todos con nuestros impuestos, etc.

Isabel Cristina Zuleta: es muy importante el recuperar la sensibilidad, los sentidos, cuando estamos en este mundo tan acelerado se van perdiendo, esa sensibilidad sobre el medio que nos rodea y lo veía en Medellín con discusiones sobre el aire contaminado porque la gente no es consciente de lo que está respirando. Es muy difícil que seamos conscientes de qué tipo de aire estamos respirando y a donde quiero llegar es que una represa como esta nos afecta, así no nos demos cuenta de que nos está afectando, así no sepamos de qué manera nos está afectando, porque allá se está descomponiendo el bosque seco tropical, que está en vía de extinción en el planeta, y no solamente es el ciudadano de a pie colombiano sino que Hidroituango está afectando el planeta porque destruyó un bosque que está en vía de extinción con todas sus especies, pero además no quiso retirarlo. Nosotros hicimos hace un año una audiencia pública para exigirle que adorábamos ese bosque del cual dependía la vida pero que por lo menos lo retirara para que no produjera lo que hoy está produciendo y es la descomposición de la materia orgánica generando gas metano que no tiene fronteras y sencillamente viaja por donde viajan los aires y que va a afectar a un montón de personas que no saben que se están viendo afectadas. Entonces, en términos ambientales, lo primero que hay que decirle al ciudadano de a pie es que los daños ambientales no tienen fronteras, que el ciclo del agua es un ciclo, no es un ele- 
mento, no es un recurso, es un ciclo hídrico, entonces está afectando el ciclo hídrico, se está afectando el aire y además, lo que decían ahora, vamos a tener una deuda externa gigantesca porque Hidroituango nos ha dejado con una deuda ante el Banco Interamericano de Desarrollo, ante la banca canadiense, ante la banca belga y francesa, ante la banca alemana, ante la banca del BNS de Brasil, ante un montón de bancos de afuera que, así no nos demos cuenta, vamos a tener que pagar miles de millones de dólares por un desastre ecológico y social de estas magnitudes y eso para nosotros ¿qué implicaciones tiene? Pues sencillamente entre más gastemos en la tarifa energética pues menos vamos a tener para comer y para otras necesidades, pero además una cosa que es muy grave: nos reuníamos la semana pasada con la banca canadiense y le expresaba a los quebequenses en apoyo al movimiento la preocupación de que se pierda esa plata, esos tres mil y pico de millones de dólares y nos decía el banco una respuesta concreta: "ino se preocupen que nosotros nunca perdemos!" Así nos contestó. En el peor de los casos, primero se tiene que quebrar esa empresa, que nos dijeron que era muy buena y resulta que no. Entonces, primero vamos a tener que sufrirlo nosotros pero los bancos internacionales no van a perder y eso es así de concreto y tenemos que saber quiénes son esa banca y por último creo que el ciudadano de a pie además de todo lo que podía en las escalas de afectaciones y que a una le sorprende que haya ciudadanos que sostengan ética y moralmente que un proyecto de estos pueda continuar no solo técnicamente sino que pueda continuar existiendo, pero creo que al ciudadano de a pie si le ha generado un cuestionamiento ético y moral del deber ser, qué se debe hacer y qué no se debe hacer en Colombia, cuál es el futuro en Colombia y creo que eso es importante porque no todo es negativo. Me lo decía ahora, aquí hay que decir algo positivo: algo positivo es que hoy ustedes se están cuestionando sobre lo que debe pasar con los ríos de Colombia, como deben estar los ríos de Colombia y de quienes son los ríos de Colombia porque hay unos que se los adueñaron, se los apropiaron y con esas excusas que para nosotros son completamente ofensivas de que es el río más contaminado. Nosotros lo sabemos, es un río muy contaminado, pero no es nuestra culpa, viene contaminado de otras regiones, tiene otras responsabilidades y vienen a decirnos a nosotros que somos inconsecuentes porque no criticamos la minería, por qué no criticamos el problema de la ganadería, la respuesta que ha dado la gente es: si son tan berracos váyanse allá y háganle una protesta a esos ganaderos, a ver con quien es que están aliados ¡y nos llaman a nosotros de inconsecuentes! Váyanse allá e intenten quitar esas dragas y esas retroexcavadoras que algunos políticos de este país llamaron dizque a limpiar el río, lo dragaron en medio de la sequía y en ese dragado ilegal, que hasta donde sabemos no fue autorizado y que nosotros observamos venían mirando los peces muertos y ellos sacando las arenas del río y sacando toda la biodiversidad que había allí, no solo fueron los peces fueron un montón de situaciones que se dieron. ¿Qué es lo que está pasando? ¿Quiénes estábamos vigilando allí? Tendríamos que haber estado miles de personas, ustedes los estudiantes, los estudiosos recuperando el material genético, si fuera una empresa ética hubiera llamado a todas las universidades, como lo dice el Dr. Orlando Rangel, vamos a recuperar material genético, tenemos que hacer esto, tenemos como conservarlo, tenemos experiencia, hay procesos de comparación y habría mucho que podríamos hacer. Hoy tenemos una tarea 
distinta, es una tarea del cuestionamiento y de la redirección de lo que debe pasar con los ríos de Colombia y de lo que debe pasar con nosotros, esas comunidades ribereñas que estamos en las zonas rurales.

Orlando Rangel: ¿A quién afecta? A todos, porque Hidroituango debería generar ahora el 20\% de energía para 2019 y para el 2022 iba a duplicar, es decir el negocio siempre, la gallina de los huevos de oro. Hoy en día esos modelos hay que recalcularlos. Yo pienso que eso significa que de alguna parte tienen que salir los fondos y como dijo la Dra. Isabel, los banqueros no van a perder, ni van a poner nada, simplemente prestan para ver dónde compran y eso simplemente se va a reflejar en las tarifas de los recibos, eso es impajaritable. El gobierno acolita cuando verdaderamente no tenemos información o no tenemos buen uso de la información, bueno, para responder la pregunta. Ahora lo otro, claro que Hidroituango no solamente tiene cosas malas, también tiene cosas buenas. Voy a terminar un poco sarcástico: ustedes recordarán que el presidente Bush hijo, cuando la crisis de los incendios en California, salió por televisión y dijo: yo creo que lo mejor es que terminemos con todo el bosque y con eso no hay incendios, una salida muy clara, cual es el problema.

Nosotros trabajamos los últimos 12 años las ciénagas del Caribe especialmente Córdoba y Cesar y sabemos el tiempo de vida media de las ciénagas. Las ciénagas del Cesar están condenadas por que reciben agua del río Magdalena y el río Santander llenos de sedimentos, la solución serían trampas de sedimentos, pero no se va a hacer, entonces la mayoría de estas ciénagas tienen 100 o 200 años de vida, no hay nada que hacer. Además es una cosa natu- ral, todos los ambientes lénticos-cienagas del mundo se tienen que secar porque depende de la tasa media de sedimentación, evaporación y esto está completamente documentado; entonces esas ciénagas del Caribe tienen una vida media muy bajita porque son muy poco profundas y reciben una gran carga de sedimentos. Con Hidroituango estamos seguros que se van a salvar el resto de ciénagas cuenca abajo porque ya no van a recibir esa carga de sedimentos porque eso es una trampa de sedimentos, en las notas de prensa dicen que el agua sale clarita, por supuesto, pero a qué costo por Dios, a la muerte de un río, sin embargo, algunas de las ciénagas van a permanecer porque no hay sedimentación. En el Caribe tenemos sedimentación que si acá hubiera consciencia ya hubiéramos tomado una determinación, tenemos hasta un metro de sedimento por año en las ciénagas del Cesar y en parte del Magdalena, eso llamaría la atención inmediatamente. Las ciénagas están muertas por que el río Magdalena, entre otros, lo único que hacen es cargar sedimentos y entonces, pues pongamos una trampa de sedimentos, hacemos bastantes Hidroituangos y ahí si salvaríamos nuestras Ciénagas.

Hernán Sánchez Cruz: si el proyecto logra una recuperación y no entra en operación tenemos otras alternativas como las termoeléctricas. Puede valer 1,5 veces más que lo que cuesta una hidroeléctrica; si se hace con Diesel sería aproximadamente seis veces más. La empresa EPM está haciendo todo el esfuerzo para lograr recuperar y poner a operar, pero si no se logra, pierde todas las transferencias que se entregan al municipio; se pierde todo el dinero de transferencias que obliga a la protección de cuencas. Para la protección de las áreas intervenidas son 55 mil millones; referente a las 
compensaciones, son 17.000 y 8.000 hectáreas. Frente a lo que menciona Isabel Cristina Zuleta del rescate de peces, fue imposible por las condiciones de orden público, en la zona se dio un enfrentamiento cerca de donde estaban los equipos trabajando, entonces también es bueno que se tenga en cuenta esa condición. La empresa siempre ha venido trabajando para la recuperación, para la mitigación de los impactos. El manejo de caudales desde las hidroeléctricas Porce 2 y Porce 3 con miras a mitigar esta problemática, hay plataformas donde pueden mirar las condiciones del río y pueden comparar durante los diferentes años secos y cómo es la condición en esa zona. Es importante tener en cuenta todos estos aspectos. Afortunadamente, pues hubo visita de todos los entes de control Procuraduría, Contraloría, las autoridades ambientales evidenciaron, de hecho, si no se hubieran recuperado los peces se habría dado una problemática en salubridad, entonces es bueno dejar eso en el contexto de la gente.

\section{Conclusiones:}

La contextualización puso de manifiesto varias realidades que generalmente se soslayan, como el desconocimiento de que los territorios contienen comunidades que están construyendo una vida ahí, tienen redes sociales, formas de generar su subsistencia, pequeñas economías locales. En el caso de Hidroituango las comunidades no fueron tenidas en cuenta ni a la hora de la planeación, ni la de la ejecución. Peor aún, ha habido amenazas, hostigamientos, criminalización de la protesta, asesinatos selectivos, masacres y múltiples formas de despojo.
Al conversatorio se invitaron tres académicos, una líder social y un alto funcionario de EPM. Los cinco construyeron reflexiones y posibles vías de solución. Unos en defensa de la institucionalidad, representada por EMP, otros mostrando la situación de los pobladores despojados de sus medios de subsistencia. Todos, al unísono, preocupados por los fuertes impactos que este megaproyecto tiene en la dimensión ambiental, política, social y económica de la región y del país. Y por los megaproyectos de infraestructura, en general, a los que podrían juntarse los de minería a gran escala y monocultivos que están arrasando con la biodiversidad, y dejan unos enormes pasivos ambientales que posteriormente todos debemos asumir y benefician a unos pocos en detrimento de la vida de miles de personas.

\section{Referencias}

Agencia Prensa Rural (2019). 62 masacres en los 12 municipios donde se desarrolla proyecto Hidroituango. Recuperado de: https://lanuevaprensa.com.co/component/ k2/62-masacres-en-los-12-municipios-donde-se-desarrolla-proyecto-hidroituango

Cardona, C. A.; Pinilla, M. \& Gálvez, A. (2016). ¡A un lado, que viene el progreso! Construcción del proyecto Hidroituango en el cañón del Cauca medio antioqueño, Colombia. En Ulloa, A. \& Coronado, S. (eds.) (2016). Extractivismos y posconflicto en Colombia: retos para la paz territorial. Bogotá: Universidad Nacional de Colombia. Recuperado de: https://www.cinep.org.co/ 
publicaciones/PDFS/20160801.extractivismos_posconflicto_completo.pdf\#page $=298$

EPM (2017). Proyecto hidroeléctrico Ituango. Recuperado de: http://www.grupo-epm. com

Fernández, J. C. \& Caballero, M. (2011). El despojo como progreso en Colombia. En Observatorio de Multinacionales en América Latina, OMAL, Recuperado de: http:// omal.info/spip.php?article543

Gómez Chavarría, A. (2015). Conflictos socioambientales alrededor de la hidroeléctrica Hidroituango. Tesis de grado Sociología. Universidad de Antioquia, Medellín.

Revista Semana (2019). La JEP busca la verdad sobre desaparecidos en zona de Hidroituango. 10 de agosto de 2019. Recuperado de: https://www.semana.com/nacion/articulo/la-jep-busca-la-verdad-sobre-desaparecidos-en-zona-de-hidroituango/635170

Rivera Marín, D. (2019). Cauca, el poderoso río que el hombre secó. Revista Semana, 2 de febrero de 2019. Recuperado de: https://www.semana.com/Item/ArticleAsync/600377

Rutas del conflicto (2019). En Recuperado de: http://rutasdelconflicto.com/interna. php? masacre $=667$

Torres, M. A., Caballero, J. H. \& Awad, G. (2016). Hidroeléctricas e impactos socioambientales Caso de estudio: Hidroeléctrica Ituango. Iberoamerican Journal of Project Management, 7(1), 94-115.
Vidas silenciadas (2013). Recuperado de: https://vidassilenciadas.org/hechos/2113/ 